\title{
Optimizing Thermal Behavior of Flat Plate Heat Exchanger Tube by Varying Geometrical Configuration
}

\author{
Nitesh Kumar Singh \\ M. Tech. Scholar \\ Millennium Institute of Technology, Bhopal \\ India \\ niteshsingh141@gmail.com
}

\author{
N. V. Saxena \\ Professor \\ Millennium Institute of Technology, Bhopal \\ India \\ nishant.mgi@gmail.com
}

\begin{abstract}
A plate fin heat exchanger is a type of heat exchanger design that uses plates and finned chambers to transfer heat between liquids. It is often classified as a compact heat exchanger to emphasize the relatively high ratio between the heat transfer surface and the volume. The main objective of the present work is to investigation of optimum design of plate fin tube heat exchanger using Computational fluid dynamic approach and maximizing thermal performance. There are total five designs of plate fin and tube heat exchanger are used in present work and CFD analysis have been performed in it to get maximum heat transfer. It has been observed from CFD analysis that the maximum heat transfer can be achieved from plate fin and tube heat exchanger with elliptical tube arrangement inclined at $30^{\circ}$ with $23.22 \%$ more heat transfer capacity as compared to circular tube plate pin heat exchanger. So that it is recommended that if the plate fins and tube heat exchanger with inclined elliptical tube used in place of circular tube arrangement, batter heat transfer can be achieved.
\end{abstract}

Keywords: Plain fin; Turbulence; Friction factor; etc.

\section{INTRODUCTION}

A plate fin heat exchanger is a type of heat exchanger design that uses plates and finned chambers to transfer heat between liquids. It is often classified as a compact heat exchanger to emphasize the relatively high ratio between the heat transfer surface and the volume. The plate fin heat exchanger is widely used in many sectors, including the aerospace one, due to its compact size and light properties, as well as cryotechnics, where its ability to facilitate the transfer of heat is used with small differences in temperature [1].

Plate heat exchangers in finned aluminum alloy, often called welded aluminum heat exchangers, have been used in the aviation industry for over 60 years and have been adopted in the cryogenic separation sector. Air in chemical plants such as the processing of natural gas during the Second World War and immediately afterwards. They are also used in railway engines and motor vehicles. The stainless steel fins have been used in aircraft for 30 years and are currently being established in chemical plants.

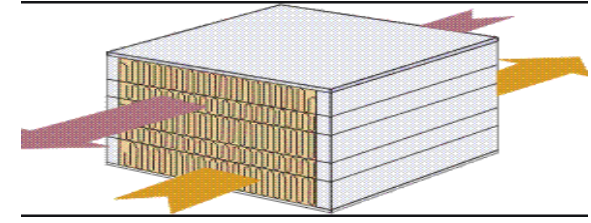

Fig. 1 Plate fin heat exchanger

Plate fin-and-tube heat exchangers are used extensively in heating, ventilating, and air conditioning (HVAC), process engineering, and refrigeration applications such as compressor intercoolers, fan coils, and air-coolers. The governing thermal resistance for heat exchangers is typically located on the air side, accounting for $85 \%$ or more of the total resistance in practical applications.

\section{LITERATURE REVIEW}

BasimFreegah et al. [1] The study showed that finned heat sinks with corrugated vertical semicircular pins exposed to parallel flow and finned heat sinks with symmetrical hollow semicircular pins in a vertical arrangement that are exposed to vertical flow the impact has superior thermal performance compared to other configurations. The old design offers a base temperature and thermal resistance reduction of approximately $25.1 \%$ and $29 \%$, respectively, and an increase in the Nusselt number of approximately 
$34.48 \%$ instead of the ribs of the conventional profile plate threaded. For the latter project, the base temperature and thermal resistance were reduced by approximately $22.6 \%$ and $25.7 \%$ respectively, while the Nusselt number shows values increasing by approximately $31.6 \%$.

hang-Hyo Son et al. [2] the single-phase convection heat transfer coefficients were calculated in this work using the modified Wilson diagram method and the pressure drop relative to other correlations. The main results are summarized as follows. The pressure drop corresponds well to the previous correlation, but the convection heat transfer coefficients differ from the others. Based on the experimental results, a new correlation of the single-phase heat transfer for the plate fin heat exchanger is presented. Máté PETRIK et al. [3] the aim of this work is to perform parametric analysis of the thermal power of a compact car cooler using computer-assisted fluid dynamics. The results show that the relationship between the pitch of the slats, the thickness of the walls of the slats, the number of slats, the depth of flow and the geometry of the tube are the main factors of heat transfer. The main goal is to find a reliable correlation of the $\mathrm{Nu}$ number for this type of heat exchanger. Also, when using this feature, the goal is to find the optimal shape of the chiller, which can lower the coolant temperature to the required value and have the lightest weight.

Abhishek Tiwari et al. [4] In the field of cryogenics, heat exchangers with a maximum efficiency of the order of 0.96 or more are used to maintain the low temperature effect generated. The compact heat exchanger (CHE) is modified by cross-flow channels between a small volume and a high rate of energy exchange between two liquids. The thermo-hydraulic performance of the compact heat exchangers (CHE) strongly depends on the Colburn fins ' $\mathrm{j}$ ' and Fanning factor ' $\mathrm{f}$ ', the triangular and rectangular perforated fins.

\section{OBJeCTIVES}

* The main objective of the present work to perform computational Fluid Dynamics simulations to predict the effect of inlet air flow maldistribution on the design and thermal hydraulic performance of heat exchanger.

* To create new model of plate fin and tube heat exchanger with different tube pitches for batter heat transfer.

* To perform computational fluid dynamics simulations to predict the effect of inlet air flow maldistribution on the new design and thermal hydraulic performance of heat exchangers.

* To compare the results from both computational fluid dynamic analysis and validate with base paper.

\section{Methodology}

\section{A. Steps of Expected Methodology}

1. Acquiring the design dimensions of Plate fin-andtube heat exchangers.

2. Preparing the CAD model of Plate fin-and-tube heat exchangers.

3. Assigning the selected material to the Plate fin and tube heat exchangers in ANSYS Software.

4. Assigning the suitable boundary conditions.

5. Further CFD analysis will be perform for base paper model and proposed model of Plate fin and tube heat exchangers.

\section{B. FEM analysis}

The use of finite element method as a tool to solve various engineering problems in industrial applications is quite a new concept. ANSYS is generally used in general purpose finite element analysis program. The construction of solution to engineering problems using FEM requires development of computer program based on FEM formulation or commercially available FEM program like ANSYS.

C. Algorithm used for Computational fluid dynamics analysis

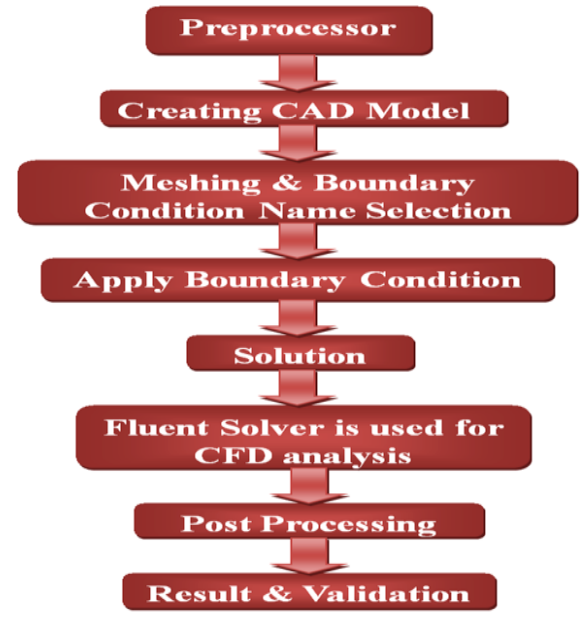

Fig. 2: Algorithm used for Computational fluid dynamics analysis

\section{Steps of computational fluid dynamics Analysis:}

The different analysis steps involved in computational fluid dynamics Analysis are mentioned below.

1. Preprocessor

A. Creation of CAD Model:

B. Generation of Meshing: 
C. Define Materials:

2. Solution Processor: In this phase of analysis the computer takes over and solves the instantaneous equation which is generated by finite element method.

Postprocessor: Reviewing analysis results over the entire model is done in the general postprocessor.

\section{E. Governing Equations}

1. Conservation of mass or continuity equation:

The equation for conservation of mass, or continuity equation, can be written as follows:

$$
\frac{\partial \rho}{\partial t}+\nabla \cdot(\rho \vec{v})=S_{m}
$$

Where $S_{m}=$ mass added to the continuous phase or any user defined sources.

For 2D axisymmetric geometries, the continuity equation is given by

$$
\frac{\partial \rho}{\partial t}+\frac{\partial}{\partial x}\left(\rho v_{x}\right)+\frac{\partial}{\partial r}\left(\rho v_{r}\right)+\frac{\rho v_{r}}{r}=S_{m}
$$

Where $x$ is the axial coordinate, $r$ is the radial coordinate, $v_{x}$ is the axial velocity, and $v_{r}$ is the radial velocity.

\section{Momentum Conservation Equations}

Conservation of momentum in an inertial reference frame is described by

$$
\frac{\partial}{\partial t}(\rho \vec{v})+\nabla \cdot(\rho \vec{v} \vec{v})=-\nabla p+\nabla \cdot(\overline{\bar{\tau}})+\rho \vec{g}+\vec{F}
$$

Where $\mathrm{p}=$ static pressure

$\overline{\bar{\tau}}=$ stress tensor,

$\rho \vec{g}=$ gravitational body force and

$\vec{F}=$ external body forces

The stress tensor $\overline{\bar{\tau}}$ is given by

$$
\overline{\bar{\tau}}=\mu\left[\left(\nabla \vec{v}+\nabla \vec{v}^{\mathrm{T}}\right)-\frac{2}{3} \nabla \cdot \vec{v} I\right]
$$

where $\mu=$ molecular viscosity

$I=$ unit tensor,

For 2D axisymmetric geometries, the axial and radial momentum conservation equations are given by

$$
\begin{aligned}
& \qquad \begin{aligned}
\frac{\partial}{\partial x}\left(\rho v_{x}\right)+\frac{1}{r} \frac{\partial}{\partial x}\left(r \rho v_{x}\right. & \left.v_{x}\right)+\frac{1}{r} \frac{\partial}{\partial r}\left(r \rho v_{r} v_{r}\right) \\
= & -\frac{\partial p}{\partial x}+\frac{1}{r} \frac{\partial}{\partial x}\left[r \mu\left(2 \frac{\partial v_{x}}{\partial x}-\frac{2}{3}(\nabla \cdot \vec{v})\right)\right] \\
& +\frac{1}{r} \frac{\partial}{\partial r}\left[r \mu\left(\frac{\partial v_{x}}{\partial r}+\frac{\partial v_{r}}{\partial x}\right)\right]+F_{x}
\end{aligned} \\
& \text { And } \quad \begin{aligned}
\frac{\partial}{\partial t}\left(\rho v_{r}\right)+\frac{1}{r} \frac{\partial}{\partial x}\left(r \rho v_{x} v_{r}\right) & +\frac{1}{r} \frac{\partial}{\partial r}\left(r \rho v_{r} v_{r}\right) \\
& =-\frac{\partial p}{\partial r}+\frac{1}{r} \frac{\partial}{\partial x}\left[r \mu\left(\frac{\partial v_{r}}{\partial x}+\frac{\partial v_{x}}{\partial r}\right)\right] \\
& +\frac{1}{r} \frac{\partial}{\partial r}\left[r \mu\left(2 \frac{\partial v_{r}}{\partial r}-\frac{2}{3}(\nabla \cdot \vec{v})\right)\right]-2 \mu \frac{v_{r}}{r^{2}} \\
& +\frac{2 \mu}{3 r}(\nabla \cdot \vec{v})+\rho \frac{v_{z}^{2}}{r}+F_{r}
\end{aligned}
\end{aligned}
$$

Where

$$
\nabla \cdot \vec{v}=\frac{\partial v_{x}}{\partial x}+\frac{\partial v_{r}}{\partial r}+\frac{v_{r}}{r}
$$

Where $v_{x}=$ Axial velocity

$v_{r}=$ Radial velocity

$\boldsymbol{v}_{\mathbf{z}}=$ swirl velocity

3. Energy Equation

The energy equation for the mixture takes the following form:

$$
\frac{\partial}{\partial t} \sum_{k=1}^{n}\left(\alpha_{k} \rho_{k} E_{k}\right)+\nabla \cdot \sum_{k=1}^{n}\left(\alpha_{k} \vec{v}_{k}\left(\rho_{k} E_{k}+p\right)\right)=\nabla \cdot\left(k_{e f f} \nabla T\right)+S_{E}
$$

where $k_{e f f}=$ effective conductivity

$S_{E}=$ volumetric heat sources

Where

$$
E_{k}=h_{k}-\frac{p}{\rho k}+\frac{v_{k}^{2}}{2}
$$

$E_{k}=h_{k}$ for an incompressible phase and $h_{k}=$ sensible enthalpy for phase $k$

$k-\in$ model:

The turbulence kinetic energy, $k$, and its rate of dissipation, $\in$, are obtained from the following transport equations:

$$
\begin{aligned}
& \qquad \begin{aligned}
\frac{\partial}{\partial t}(\rho k)+\frac{\partial}{\partial x_{i}}\left(\rho k v_{i}\right) & =\frac{\partial}{\partial x_{j}}\left[\left(\mu+\frac{\mu_{t}}{\sigma_{k}}\right) \frac{\partial k}{\partial x_{j}}\right]+G_{k}+G_{b}-\rho \\
& \in-Y_{M}+S_{k}
\end{aligned} \\
& \text { and } \begin{aligned}
\frac{\partial}{\partial t}(\rho \in)+\frac{\partial}{\partial x_{i}}\left(\rho \in v_{i}\right) \\
=\frac{\partial}{\partial x_{j}}\left[\left(\mu+\frac{\mu_{t}}{\sigma_{\epsilon}}\right) \frac{\partial \in]}{\partial x_{j}}\right]+C_{1 \in} \frac{\epsilon}{k}\left(G_{k}+C_{3 \in} G_{b}\right) \\
-C_{2 \in} \rho \frac{\epsilon^{2}}{k}+S_{\epsilon}
\end{aligned}
\end{aligned}
$$

In these equations, $G_{k}$ represents the generation of turbulence kinetic energy due to the mean velocity gradients,

$G_{b}$ is the generation of turbulence kinetic energy due to buoyancy,

$Y_{M}$ represents the contribution of the fluctuating dilatation in compressible turbulence to the overall dissipation rate, $C_{1 \in}, C_{2 \epsilon}$, and $C_{3 \in}$ are constant. $\sigma_{k}$ and $\sigma_{\epsilon}$ are turbulent Prandtl numbers for $\mathrm{k}$ and $\epsilon$, $S_{k}$ And $S_{\in}$ are user-defined source terms.

F. Geometrical parameters for the plate fin tube heat exchanger models:

\begin{tabular}{lc}
\hline \multicolumn{1}{c}{ Parameters } & Values \\
\hline Tube diameter fin collector outside & 9.97 \\
diameter, $\mathrm{D}(\mathrm{mm})$ & \\
Longitudinal tube pitch, $\mathrm{L}_{\mathrm{l}}(\mathrm{mm})$ & 27.50 \\
Transverse pitch, $\mathrm{L}_{\mathrm{t}}(\mathrm{mm})$ & 31.75 \\
Fin Pitch, $\mathrm{F}_{\mathrm{p}}(\mathrm{mm})$ & 3.21 \\
Fin Thickness, $\mathrm{F}_{\mathrm{t}}(\mathrm{mm})$ & 0.20 \\
\hline
\end{tabular}




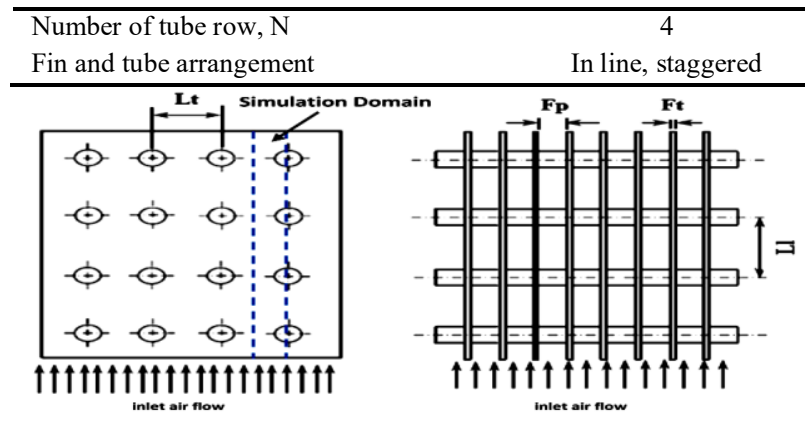

Fig.3: Physical model with staggered arrangement

Because of the symmetry of the tube bank geometry, only a portion of the domain needs to be modeled. The computational domain is shown in outline in Fig

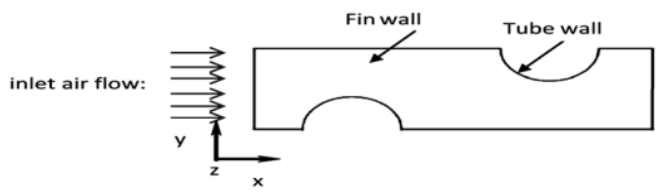

Fig. 4: computational domain with different boundaries of fin tube heat exchanger

G. CFD Analysis of plate fin with elliptical tube inclined at $30^{\circ}$ heat exchanger

\section{CAD geometry}

In this work, a two-dimensional CAD model of a sheet metal fin with an elliptical tube inclined by $30^{\circ}$ is created using a modular design of the ANSYS workbench. According to that of the table above and the figshows a two-dimensional view of the plate fin with an elliptical tube inclined by a $30^{\circ}$ heat exchanger.

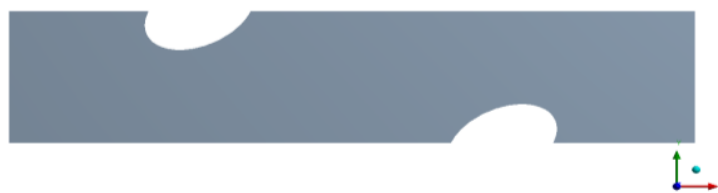

Fig. 5: CAD model of plate fin with elliptical tube inclined at 30o heat exchanger

\section{Meshing}

After completing the CAD geometry of the plate fin with an elliptical tube inclined by $30^{\circ}$, the heat exchanger is imported into the ANSYS workbench for a further calculation of the fluid dynamics. The next step is meshing. CAD geometry is divided into a large number of small parts called meshes. in this book it is 16650 and the total number of elements is 16300. The types of elements used are rectangular, which is a rectangular shape with four knots on each element.

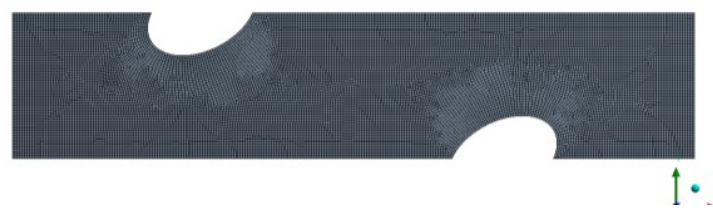

Fig. 6: Meshing of plate fin with elliptical tube inclined at 30o heat exchanger

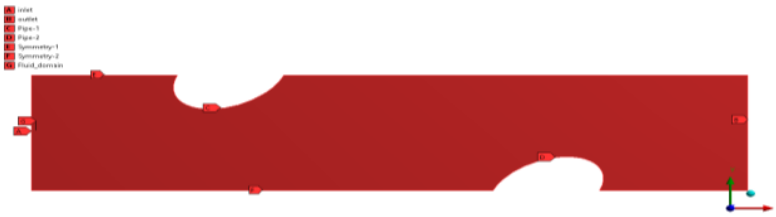

Fig. 7: Different boundaries of Plate fin with elliptical tube inclined at $30^{\circ}$ heat exchangers

\section{Quality of meshing.}

The quality of the net plays an important role in the accuracy and stability of the calculation. In this work, square elements were created during discretization. The quality of the cell, including its orthogonal quality, its proportions and its asymmetry, has a significant impact on the accuracy of the solution.

\section{Orthogonal mesh quality}

Orthogonal quality is computed for cells using the vector from the cell centroid to each of its faces, corresponding face area vector, and the vector from the cell centroid to centroids of each of the adjacent cells. The worst cells will have an orthogonal quality closer to 0 , with the best cells closer to 1 . In the present case the minimum value is 0.73761 and maximum value is 1 and average value is 0.99273 , which means the mesh quality is acceptable and very good.

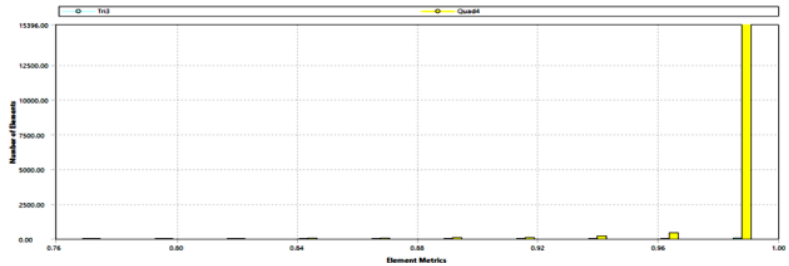

Fig. 8: Orthogonal mesh quality of Plate fin with elliptical tube inclined at $30^{\circ}$ heat exchangers

\section{Boundary condition}

- To determine the maximum temperature Plate fin with elliptical tube inclined at $30^{\circ}$ heat exchanger need to on energy equation.

- Select Second Order Upwind for the Momentum and Energy equation.

- For the creation of periodic zone following commands have to use.

$>$ mesh/modify-zones/make-periodic

Periodic zone [O]

Shadow zone [()] 
Rotational periodic? (If no, translational) [yes] no Create periodic zones? [Yes] Yes

Auto detect translation vector? [Yes] Yes

- In general setting pressure based solver is select.

- For material selection used water liquid as a working fluid having density $=998.2 \mathrm{Kg} / \mathrm{m}^{3}, \mathrm{Cp}=4182 \mathrm{~J} / \mathrm{Kg}$ $\mathrm{K}$, Thermal Conductivity $0.6 \mathrm{~W} / \mathrm{m}-\mathrm{k}$ and viscosity $\mathrm{Kg} / \mathrm{m}-\mathrm{Sec}$.

After performing computational fluid dynamic analysis on plate fin with elliptical tube inclined at $30^{\circ}$ heat exchanger the temperature distribution over the plate fin with elliptical tube inclined at $30^{\circ}$ has been observed. The temperature distribution at Plate fin and tube heat exchangers has been from $353.1 \mathrm{~K}$ to $268.9 \mathrm{~K}$ which shows the temperature drop of 84.2 degree.

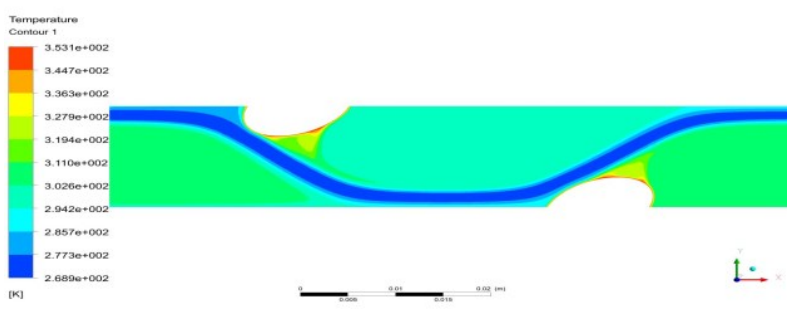

Fig. 9: Temperature distribution over the plate fin with elliptical tube inclined at $30 \mathrm{o}$ heat exchanger

After performing computational fluid dynamic analysis on plate fin with elliptical tube inclined at $30^{\circ}$ heat exchanger the velocity distribution over the plate fin with elliptical tube inclined at $30^{\circ}$ has been observed. The maximum velocity at plate fin with elliptical tube inclined at $30^{\circ}$ heat exchangers has been recorded is $15.8 \mathrm{~m} / \mathrm{sec}$.

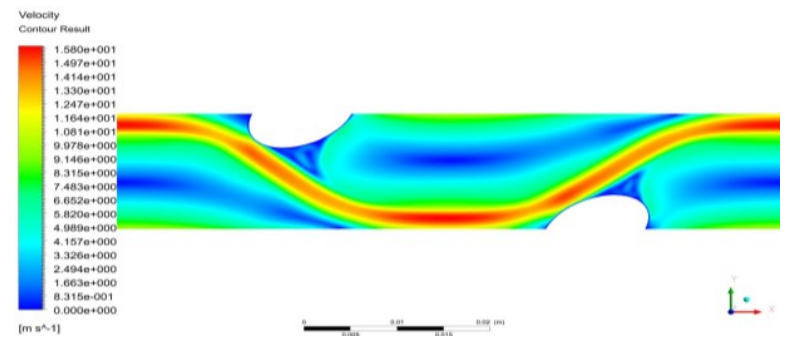

Fig. 10: Velocity distribution over the plate fin with elliptical tube inclined at 300 heat exchanger

After performing computational fluid dynamic analysis on plate fin with elliptical tube inclined at $30^{\circ}$ heat exchanger the pressure distribution over the plate fin with elliptical tube inclined at $30^{\circ}$ has been observed. The maximum pressure at over the plate fin with elliptical tube inclined at $30^{\circ}$ heat exchangers has been recorded is 89.69Pa.

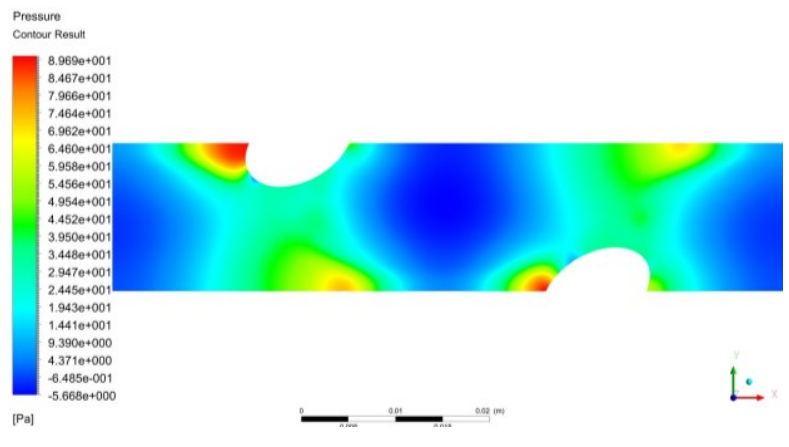

Fig. 11: Pressure distribution over the plate fin with elliptical tube inclined at $30 \mathrm{o}$ heat exchanger

Figshows the schematic air velocity vector diagram of air flowing through the plate fin with elliptical tube inclined at $30^{\circ}$ heat exchanger.

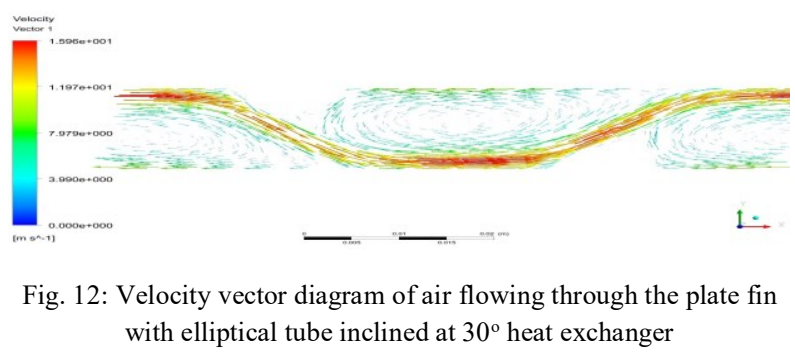

H. CFD Analysis of plate fin with circular tube heat exchanger

\section{CAD geometry}

In the present work a two dimensional CAD model of plate fin with circular tube heat exchanger is created with the help of design modular of ANSYS workbench. According to dimensional parameters given in above table no. and a two dimensional view of the plate fin with circular tube heat exchanger is shown in figure.

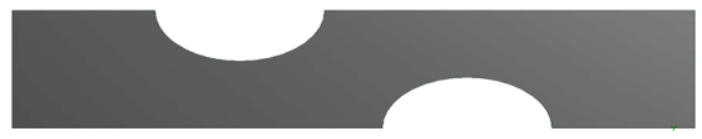

Fig. 13: CAD model of plate fin with circular tube heat exchanger

\section{Meshing}

After completing the CAD geometry of plate fin with circular tube heat exchanger is imported in ANSYS workbench for further computational fluid dynamics analysis and the next step is meshing. CAD geometry is divided into large numbers of small pieces called mesh. in the present work is 15417 and total No. of Elements is 15107. Types of elements used are rectangular which is a rectangular in shape with four nodes on each element. 


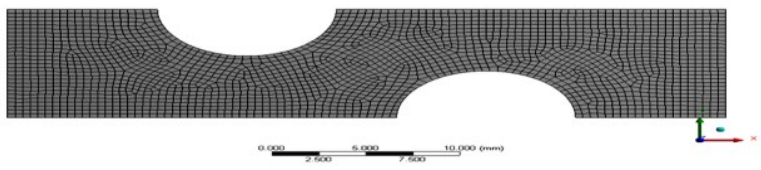

Fig. 14: Meshing of plate fin with circular tube heat exchanger

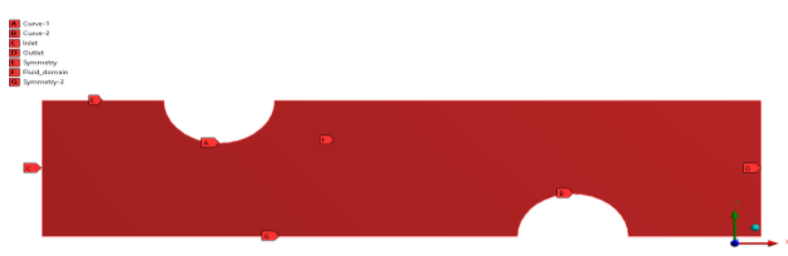

Fig. 15: Different boundaries of Plate fin with circular tube heat exchangers

\section{Quality of meshing}

The quality of the mesh plays an important role in the accuracy and stability of the calculation. In the present work the Quadrilateral elements have been generated during discretization. The quality of the cell including its orthogonal quality, aspect ratio, and skewers has an important effect on the accuracy of the solution.

\section{Factor that affect the mesh quality}

- Rate of convergence: if the mesh quality is good the rate of convergence will be grater which means the correct solution can be achieved faster.

- Solution precision: A better mesh quality provides a more precise solution.

- Computational processing time required: for the highly refined mesh the computational time will be relatively large.

- Grid Independence result: Once the computations are done and the desired property of fluid does not vary with respect to different mesh elements then it represents that further change in elements doesn't vary the results this term known as Independent Grid.

\section{Orthogonal mesh quality}

Orthogonal quality is computed for cells using the vector from the cell centroid to each of its faces, corresponding face area vector, and the vector from the cell centroid to centroids of each of the adjacent cells. The worst cells will have an orthogonal quality closer to 0 , with the best cells closer to 1 . In the present case the minimum value is 0.73761 and maximum value is 1 and average value is 0.99273, which means the mesh quality is acceptable and very good.

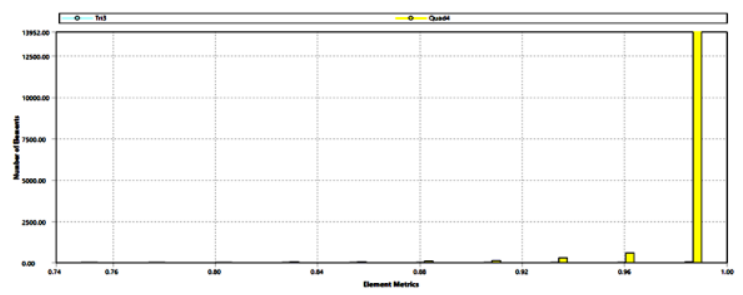

Fig. 16: Orthogonal mesh quality of Plate fin with circular tube heat exchangers

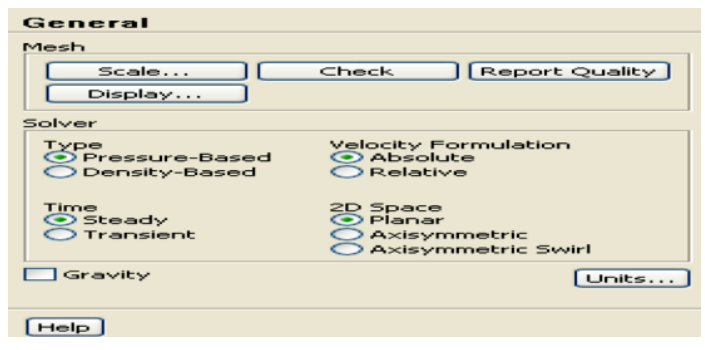

Fig. 17: general setting of fluent solver

- From the model enable energy equation.

- For material selection used water liquid as a working fluid as shown in below figure.

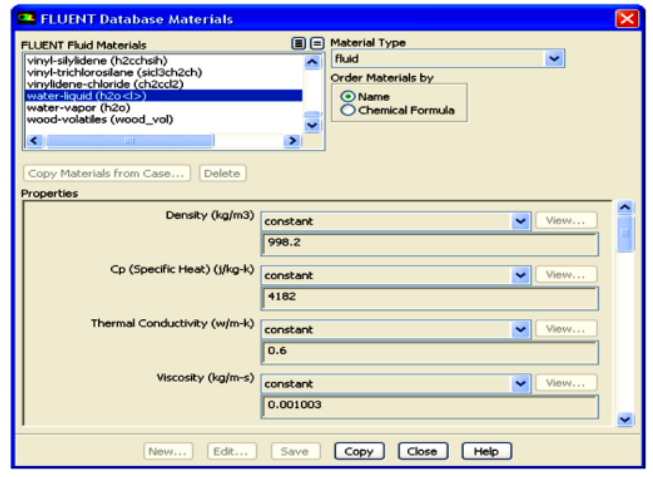

Fig. 18: material selection

After performing computational fluid dynamic analysis on plate fin with circular tube heat exchanger the temperature distribution over the plate fin with circular tube has been observed. The temperature distribution at Plate fin and tube heat exchangers has been from $353 \mathrm{~K}$ to $289 \mathrm{~K}$ which shows the temperature drop of 64 degree.

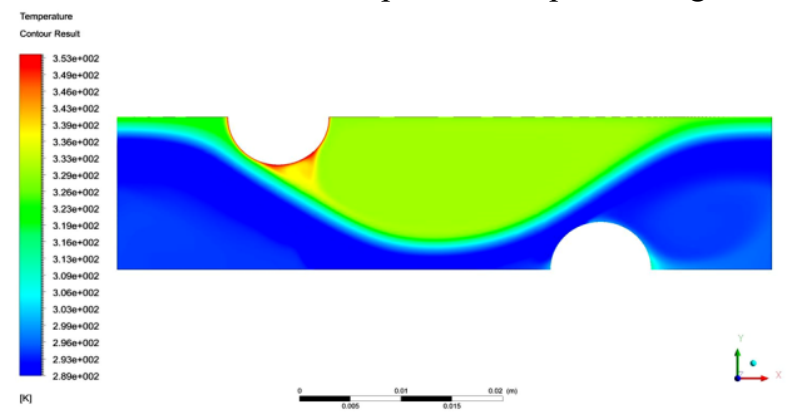


Fig. 19: Temperature distribution over the plate fin with circular tube heat exchanger

After performing computational fluid dynamic analysis on plate fin with circular tube heat exchanger the velocity distribution over the plate fin with circular tube has been observed. The maximum velocity at plate fin with circular tube heat exchangers has been recorded is $14.8 \mathrm{~m} / \mathrm{sec}$.

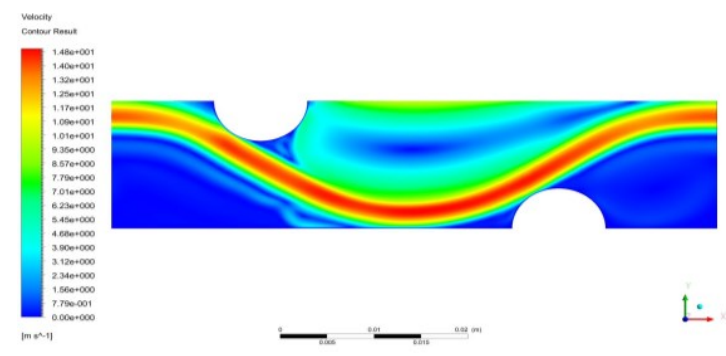

Fig. 20: Velocity distribution over the plate fin with circular tube heat exchanger

After performing computational fluid dynamic analysis on plate fin with circular tube heat exchanger the pressure distribution over the plate fin with circular tube has been observed. The maximum pressure at over the plate fin with circular tube heat exchangers has been recorded is $50.86 \mathrm{~Pa}$

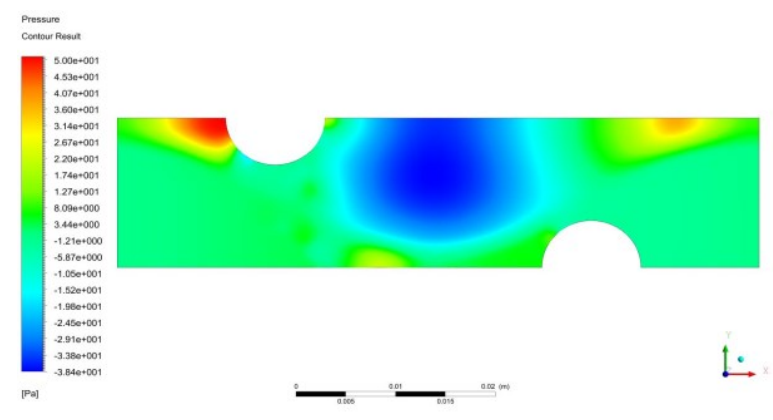

Fig. 21: Pressure distribution over the plate fin with circular tube heat exchanger

Figshows the schematic air velocity vector diagram of air flowing through the plate fin with circular tube heat exchanger.

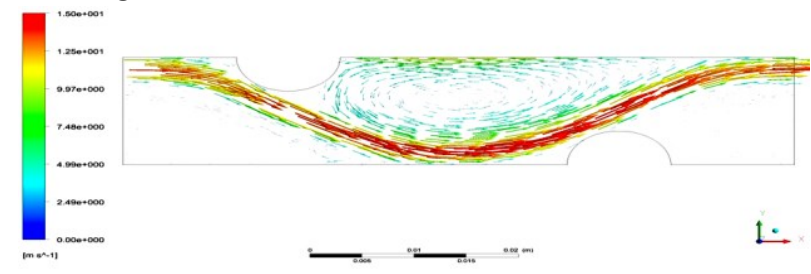

Fig. 22: Velocity vector diagram of air flowing through the plate fin with circular tube heat exchanger

I. CFD Analysis of plate fin with elliptical tube inclined at $45^{\circ}$ heat exchanger

\section{CAD geometry}

In the present work a two dimensional CAD model of plate fin with elliptical tube inclined at $45^{\circ}$ heat exchanger is created with the help of design modular of ANSYS workbench. According to dimensional parameters given in above table no. and a two dimensional view of the plate fin with elliptical tube inclined at $45^{\circ}$ heat exchanger is shown in figure.

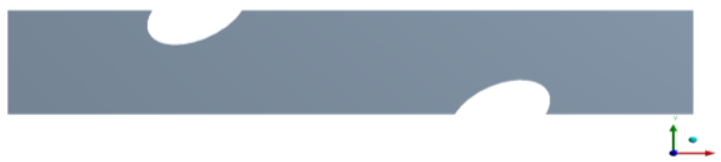

Fig. 23: CAD model of plate fin with elliptical tube inclined at 450 heat exchanger

\section{Meshing}

After completing the CAD geometry of plate fin with elliptical tube inclined at $45^{\circ}$ heat exchanger is imported in ANSYS workbench for further computational fluid dynamics analysis and the next step is meshing. CAD geometry is divided into large numbers of small pieces called mesh in the present work is 16601 and total No. of Elements is 16247. Types of elements used are rectangular which is a rectangular in shape with four nodes on each element.

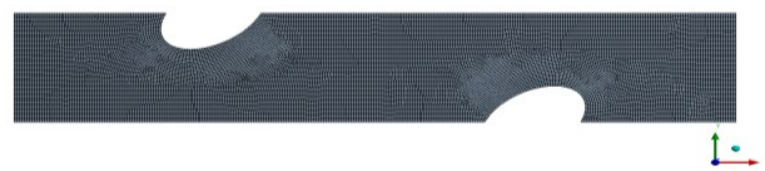

Fig. 24: Meshing of plate fin with elliptical tube inclined at 45o heat exchanger

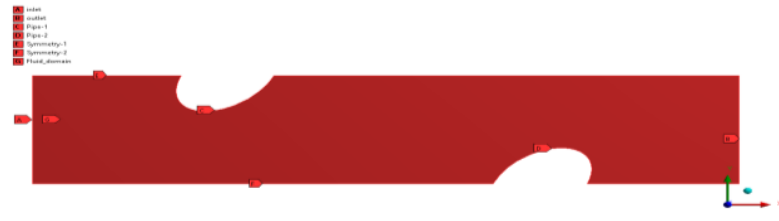

Fig. 25: Different boundaries of Plate fin with elliptical tube inclined at $45^{\circ}$ heat exchangers

\section{Quality of meshing}

The quality of the mesh plays an important role in the accuracy and stability of the calculation. In the present work the Quadrilateral elements have been generated during discretization. The quality of the cell including its orthogonal quality, aspect ratio, and skewness has an important effect on the accuracy of the solution.

\section{Orthogonal mesh quality}


Orthogonal quality is computed for cells using the vector from the cell centroid to each of its faces, corresponding face area vector, and the vector from the cell centroid to centroids of each of the adjacent cells. The worst cells will have an orthogonal quality closer to 0 , with the best cells closer to 1 . In the present case the minimum value is 0.75936 and maximum value is 1 and average value is 0.99502 , which means the mesh quality is acceptable and very good.

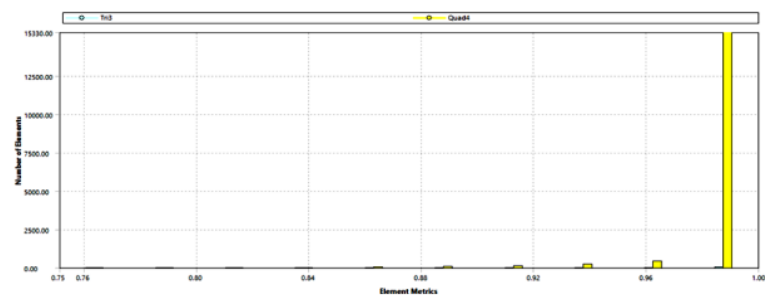

Fig. 26: Orthogonal mesh quality of Plate fin with elliptical tube inclined at $45^{\circ}$ heat exchangers

After performing computational fluid dynamic analysis on plate fin with elliptical tube inclined at $45^{\circ}$ heat exchanger the temperature distribution over the plate fin with elliptical tube inclined at $45^{\circ}$ has been observed. The temperature distribution at Plate fin and tube heat exchangers has been from $352.3 \mathrm{~K}$ to $270.3 \mathrm{~K}$ which shows the temperature drop of 82 degree.

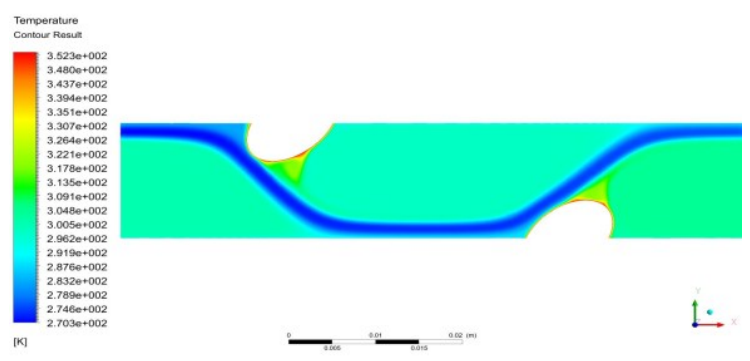

Fig. 27: Temperature distribution over the plate fin with elliptical tube inclined at $45^{\circ}$ heat exchanger

After performing computational fluid dynamic analysis on plate fin with elliptical tube inclined at $45^{\circ}$ heat exchanger the velocity distribution over the plate fin with elliptical tube inclined at $45^{\circ}$ has been observed. The maximum velocity at plate fin with elliptical tube inclined at $45^{\circ}$ heat exchangers has been recorded is $18.61 \mathrm{~m} / \mathrm{sec}$.

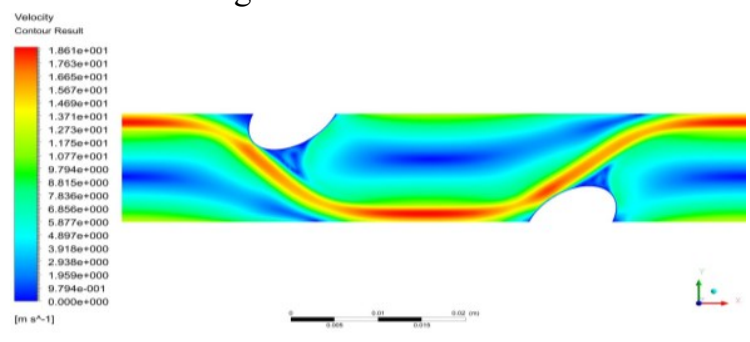

Fig. 28: Velocity distribution over the plate fin with elliptical tube inclined at $45^{\circ}$ heat exchanger

After performing computational fluid dynamic analysis on plate fin with elliptical tube inclined at $45^{\circ}$ heat exchanger the pressure distribution over the plate fin with elliptical tube inclined at $45^{\circ}$ has been observed. The maximum pressure at over the plate fin with elliptical tube inclined at $45^{\circ}$ heat exchangers has been recorded is $140.4 \mathrm{~Pa}$

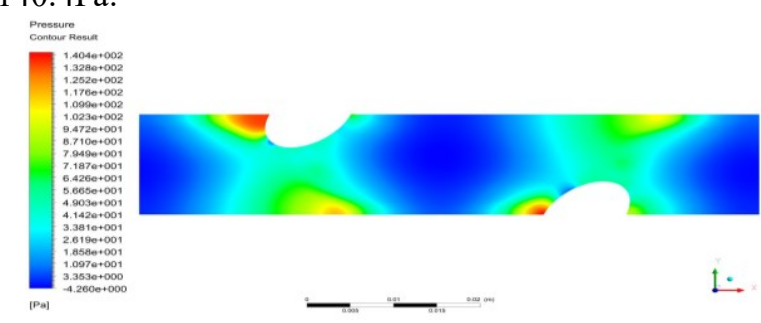

Fig. 29: Pressure distribution over the plate fin with elliptical tube inclined at $45^{\circ}$ heat exchanger

Figshows the schematic air velocity vector diagram of air flowing through the plate fin with elliptical tube inclined at $45^{\circ}$ heat exchanger.

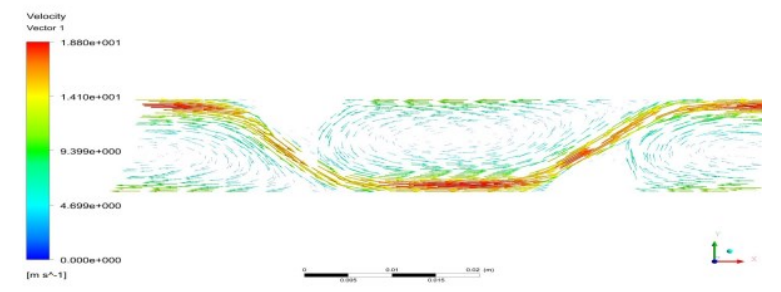

Fig. 30: Velocity vector diagram of air flowing through the plate fin with elliptical tube inclined at $45^{\circ}$ heat exchanger

\section{J. CFD Analysis of plate fin with elliptical tube inclined at $60^{\circ}$ heat exchanger \\ 1. CAD geometry}

In the present work a two dimensional CAD model of plate fin with elliptical tube inclined at $60^{\circ}$ heat exchanger is created with the help of design modular of ANSYS workbench. According to dimensional parameters given in above table no. and a two dimensional view of the plate fin with elliptical tube inclined at $60^{\circ}$ heat exchanger is shown in figure.

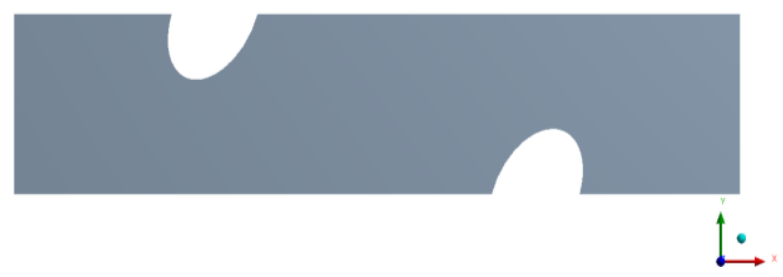

Fig. 31: CAD model of plate fin with elliptical tube inclined at $60^{\circ}$ heat exchanger 


\section{Meshing}

After completing the CAD geometry of plate fin with elliptical tube inclined at $60^{\circ}$ heat exchanger is imported in ANSYS workbench for further computational fluid dynamics analysis and the next step is meshing. CAD geometry is divided into large numbers of small pieces called mesh in the present work is 16698 and total No. of Elements is 16339. Types of elements used are rectangular which is a rectangular in shape with four nodes on each element.

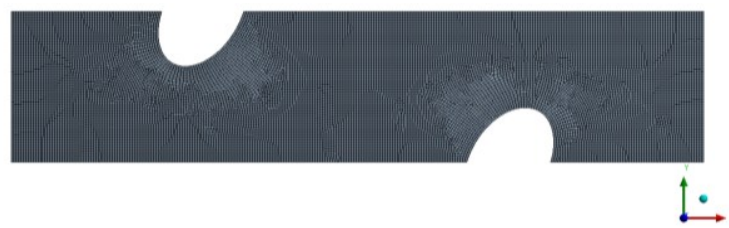

Fig. 32: Meshing of plate fin with elliptical tube inclined at $60^{\circ}$ heat exchanger

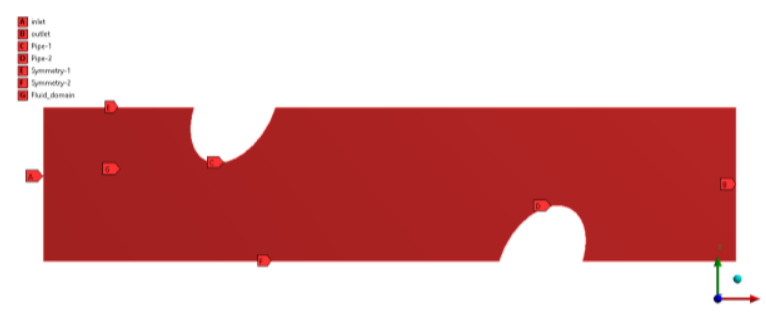

Fig. 33: Different boundaries of Plate fin with elliptical tube inclined at $60^{\circ}$ heat exchangers

\section{Quality of meshing}

The quality of the mesh plays an important role in the accuracy and stability of the calculation. In the present work the Quadrilateral elements have been generated during discretization. The quality of the cell including its orthogonal quality, aspect ratio, and skewness has an important effect on the accuracy of the solution.

\section{Orthogonal mesh quality}

Orthogonal quality is computed for cells using the vector from the cell centroid to each of its faces, corresponding face area vector, and the vector from the cell centroid to centroids of each of the adjacent cells. The worst cells will have an orthogonal quality closer to 0 , with the best cells closer to 1 . In the present case the minimum value is 0.75135 and maximum value is 1 and average value is 0.99477 , which means the mesh quality is acceptable and very good.

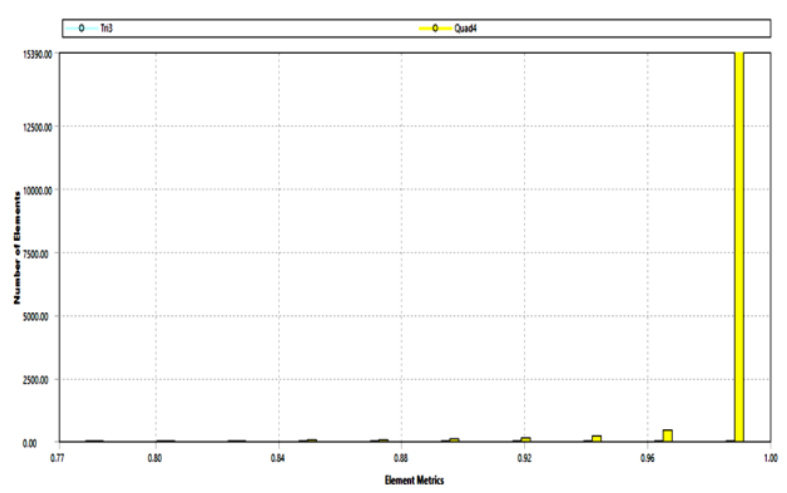

Fig. 34: Orthogonal mesh quality of Plate fin with elliptical tube inclined at $60^{\circ}$ heat exchangers

After performing computational fluid dynamic analysis on plate fin with elliptical tube inclined at $60^{\circ}$ heat exchanger the temperature distribution over the plate fin with elliptical tube inclined at $60^{\circ}$ has been observed. The temperature distribution at Plate fin and tube heat exchangers has been from $352.4 \mathrm{~K}$ to $273.7 \mathrm{~K}$ which shows the temperature drop of 78.7 degree.

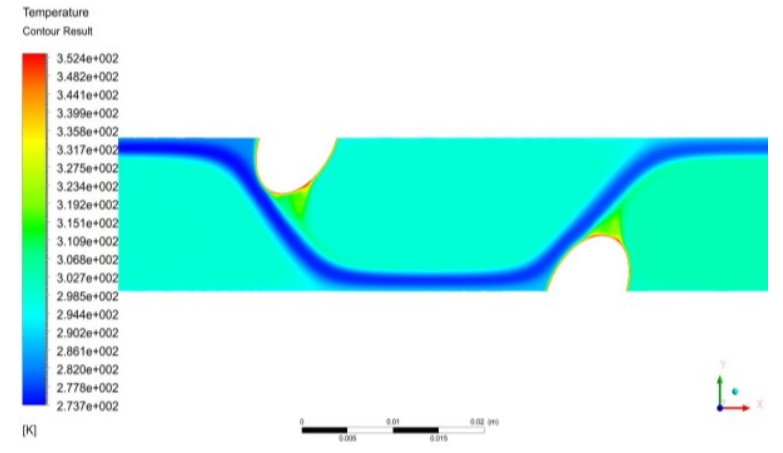

Fig. 35: Temperature distribution over the plate fin with elliptical tube inclined at $60^{\circ}$ heat exchanger

After performing computational fluid dynamic analysis on plate fin with elliptical tube inclined at $60^{\circ}$ heat exchanger the velocity distribution over the plate fin with elliptical tube inclined at $60^{\circ}$ has been observed. The maximum velocity at plate fin with elliptical tube inclined at $60^{\circ}$ heat exchangers has been recorded is $21.06 \mathrm{~m} / \mathrm{sec}$.

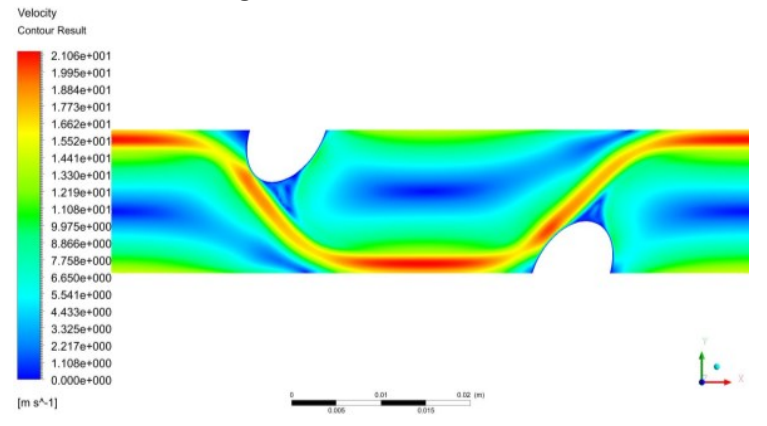


Fig. 36: Velocity distribution over the plate fin with elliptical tube inclined at $60^{\circ}$ heat exchanger

After performing computational fluid dynamic analysis on plate fin with elliptical tube inclined at $60^{\circ}$ heat exchanger the pressure distribution over the plate fin with elliptical tube inclined at $60^{\circ}$ has been observed. The maximum pressure at over the plate fin with elliptical tube inclined at $60^{\circ}$ heat exchangers has been recorded is 193.6Pa

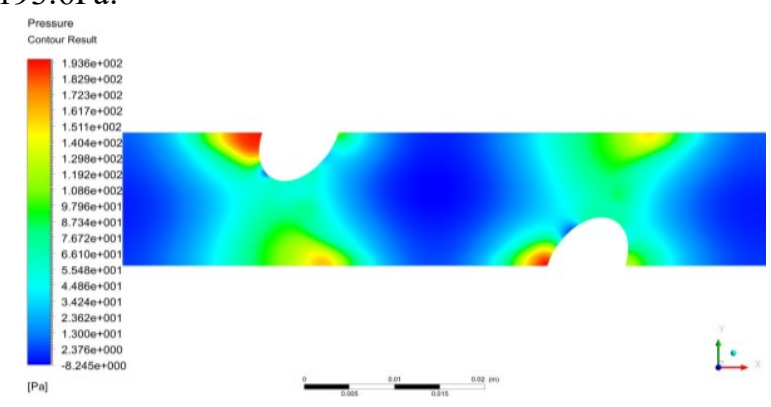

Fig. 37: Pressure distribution over the plate fin with elliptical tube inclined at $60^{\circ}$ heat exchanger

Fig shows the schematic air velocity vector diagram of air flowing through the plate fin with elliptical tube inclined at $60^{\circ}$ heat exchanger.

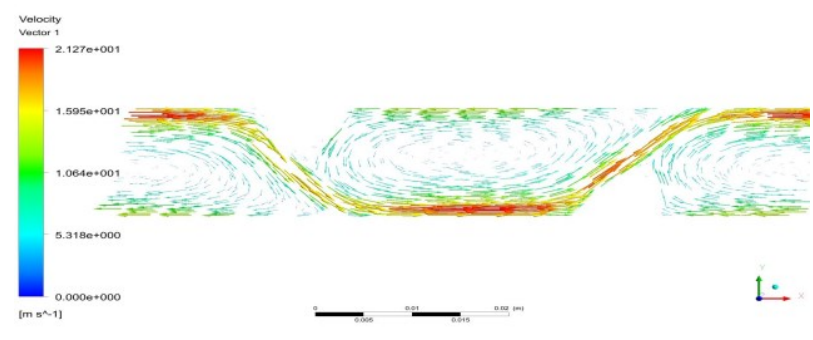

Fig. 38: Velocity vector diagram of air flowing through the plate fin with elliptical tube inclined at $60^{\circ}$ heat exchanger

K. CFD Analysis of plate fin with Vertical elliptical tube heat exchanger

1. CAD geometry

In the present work a two dimensional CAD model of plate fin with Vertical elliptical tube heat exchanger is created with the help of design modular of ANSYS workbench. According to dimensional parameters given in above table no. and a two dimensional view of the plate fin with Vertical elliptical tube heat exchanger is shown in figure.

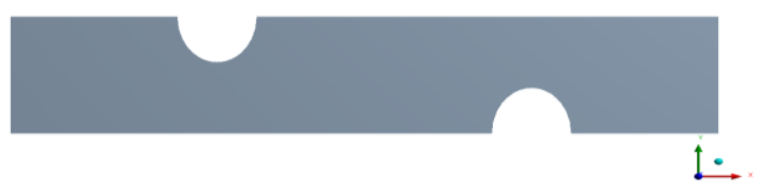

Fig. 39: CAD model of plate fin with Vertical elliptical tube heat exchanger

\section{Meshing}

After completing the CAD geometry of plate fin with Vertical elliptical tube heat exchanger is imported in ANSYS workbench for further computational fluid dynamics analysis and the next step is meshing. CAD geometry is divided into large numbers of small pieces called mesh. in the present work is 16663 and total No. of Elements is 16303. Types of elements used are rectangular which is a rectangular in shape with four nodes on each element.

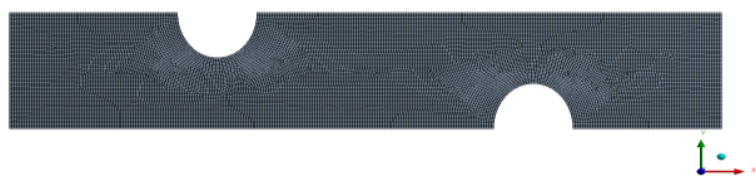

Fig. 40: Meshing of plate fin with Vertical elliptical tube heat exchanger
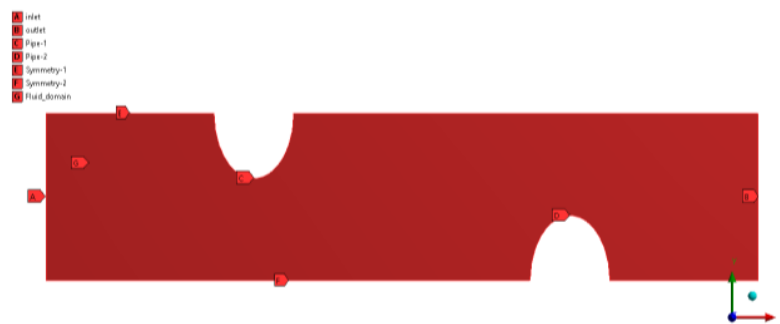

Fig. 41: Different boundaries of Plate fin with Vertical elliptical tube heat exchangers

\section{Quality of meshing}

The quality of the mesh plays an important role in the accuracy and stability of the calculation. In the present work the Quadrilateral elements have been generated during discretization. The quality of the cell including its orthogonal quality, aspect ratio, and skewness has an important effect on the accuracy of the solution.

4. Orthogonal mesh quality

Orthogonal quality is computed for cells using the vector from the cell centroid to each of its faces, corresponding face area vector, and the vector from the cell centroid to centroids of each of the adjacent cells. The worst cells will have an orthogonal quality closer to 0 , with the best cells closer to 1 . In the present case the minimum value is 0.70991 and maximum value is 1 and average value is 0.9948 , which means the mesh quality is acceptable and very good. 


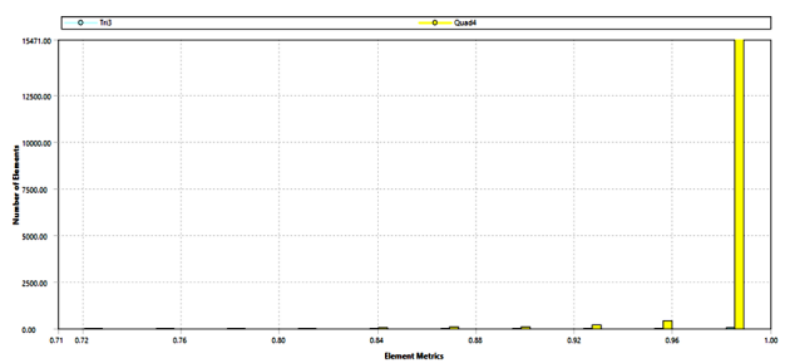

Fig. 42: Orthogonal mesh quality of Plate fin with Vertical elliptical tube heat exchangers

After performing computational fluid dynamic analysis on plate fin with Vertical elliptical tube heat exchanger the temperature distribution over the plate fin with Vertical elliptical tube has been observed. The temperature distribution at Plate fin and tube heat exchangers has been from $352.4 \mathrm{~K}$ to $274.3 \mathrm{~K}$ which shows the temperature drop of 78.1 degree.
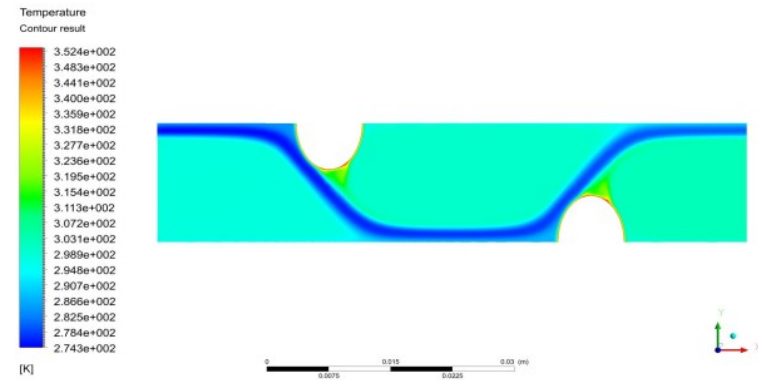

Fig. 43: Temperature distribution over the plate fin with Vertical elliptical tube heat exchanger

After performing computational fluid dynamic analysis on plate fin with Vertical elliptical tube heat exchanger the velocity distribution over the plate fin with Vertical elliptical tube has been observed. The maximum velocity at plate fin with Vertical elliptical tubeheat exchangers has been recorded is $22.13 \mathrm{~m} / \mathrm{sec}$.
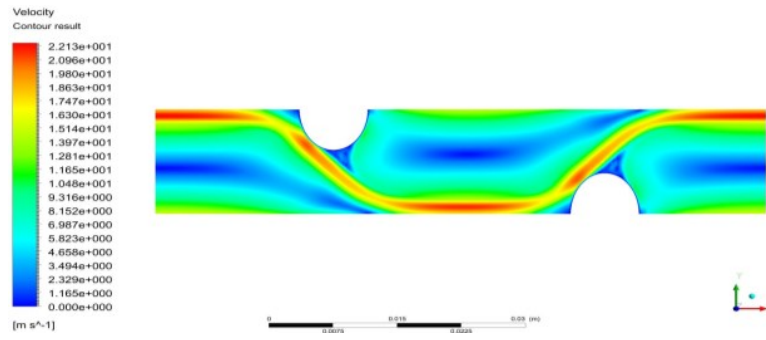

$$
\stackrel{1 \cdot}{\longrightarrow}
$$

Fig. 44: Velocity distribution over the plate fin with Vertical elliptical tube heat exchanger

After performing computational fluid dynamic analysis on plate fin with Vertical elliptical tube heat exchanger the pressure distribution over the plate fin with Vertical elliptical tube has been observed. The maximum pressure at over the plate fin with Vertical elliptical tubeheat exchangers has been recorded is $220.8 \mathrm{~Pa}$.

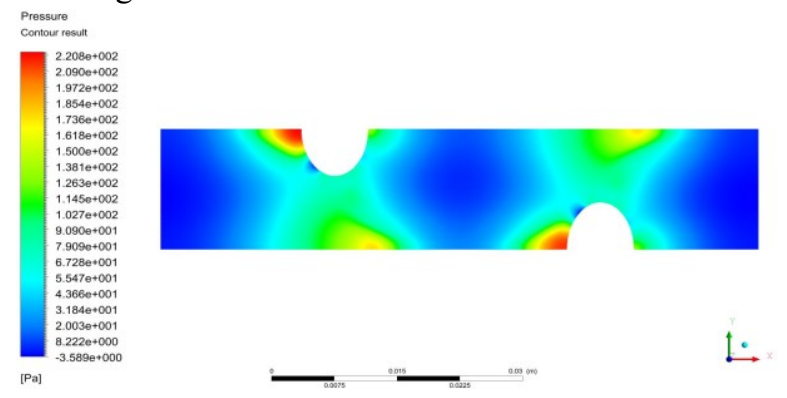

Fig. 45: Pressure distribution over the plate fin with Vertical elliptical tube heat exchanger

Fig shows the schematic air velocity vector diagram of air flowing through the plate fin with Vertical elliptical tube heat exchanger.
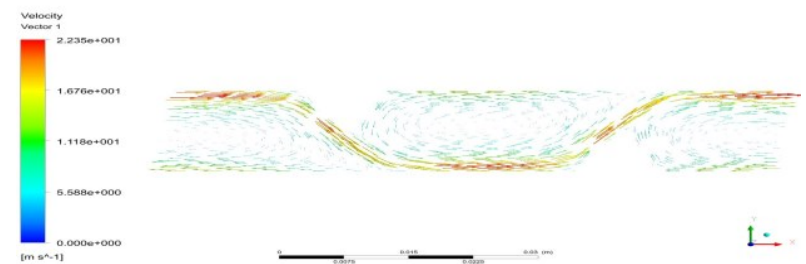

Fig. 46: Velocity vector diagram of air flowing through the plate fin with Vertical elliptical tube heat exchanger

\section{Result And Discussion}

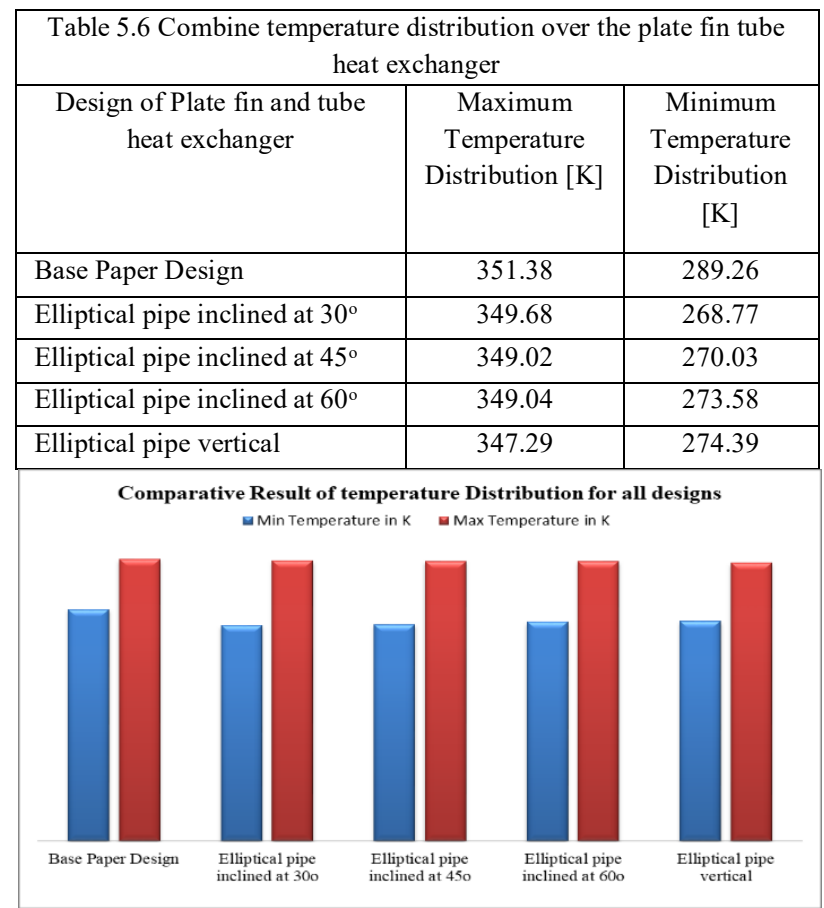

Fig. 47: Comparative Result of temperature Distribution for all designs

Table 5.7 Comparison of Performance improvement for plate fin tube heat exchanger 


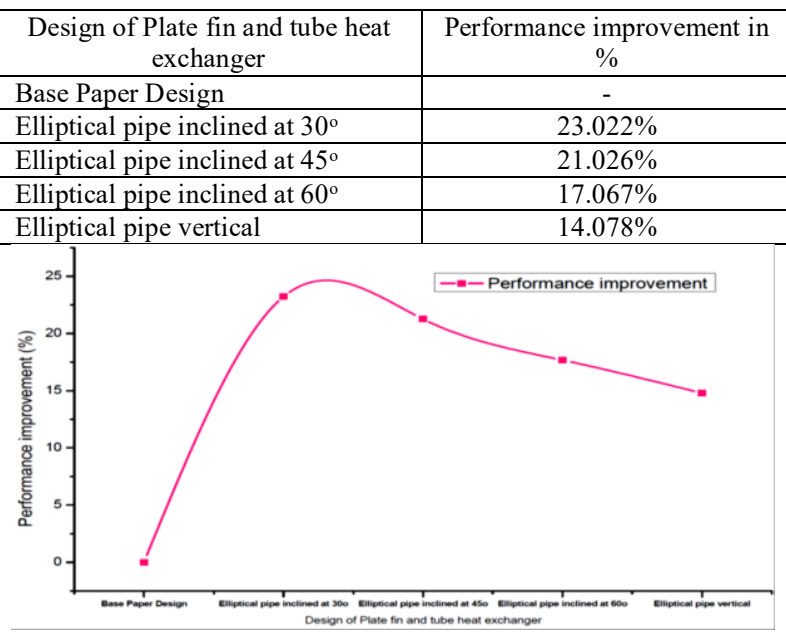

Fig. 48: Comparison of Performance improvement for plate fin tube heat exchanger

From the above results, it was observed that the maximum and minimum temperature for the design of the base paper (plate fin and tube heat exchanger with circular tube arrangement) was $351.38 \mathrm{~K}$ and $289,26 \mathrm{~K}$ per exchanger finned and tube heat exchanger with elliptical tube arrangement. An inclination of $30^{\circ}$ was observed at $349.68 \mathrm{~K}$ and $268.77 \mathrm{~K}$ for fin and tube heat exchangers with an arrangement of $45^{\circ}$ inclined elliptical tubes at $349.02 \mathrm{~K}$ and $270.03 \mathrm{~K}$ for heat exchangers heat with fins and tubes with an arrangement of elliptical tubes inclined at $60^{\circ} 349.04 \mathrm{~K}$ and $273.48 \mathrm{~K}$ and for heat exchangers with fins and tubes with an arrangement of the elliptical tube inclined at $90^{\circ}$ (vertical ellipse) were observed $347.29 \mathrm{~K}$ and $274.29 \mathrm{~K}$, respectively. It has also been observed that the heat transfer capacity for plate fins and tube heat exchangers with an arrangement of elliptical tubes inclined by $30^{\circ}$ with respect to the basic design of the paper is $23.022 \%$, for plate fins and tube heat exchangers with an elliptical arrangement of the tube inclined by $45^{\circ}$ with respect to the basic design of the paper, the value is $21.026 \%$ for plate fins and tube heat exchangers with an arrangement of the inclined elliptical tubes of $60^{\circ}$ compared to the basic design of the paper is $17.067 \%$ and for the plate fins and tube heat exchangers with an elliptical tube arrangement inclined by $90^{\circ}$ (vertical ellipse) the basic design of the paper is $14.078 \%$.

\section{CONCLUSION}

The main objective of the study of the optimal design of plate and fin heat exchangers through a computer-assisted fluid-dynamic approach and the maximization of thermal power. After performing a computerized analysis of fluid dynamics on various plate and fin heat exchanger designs, the following conclusions were drawn.

- The maximum and minimum temperature for the base paper design (flat tube heat exchanger and circular tube heat exchanger) was observed at 351.38 $\mathrm{K}$ and $289.2626 \mathrm{~K}$, therefore the temperature difference is 62.12 degrees.

- The maximum and minimum temperature for heat exchangers with plate fins and tubes with an arrangement of the elliptical tube inclined by $30^{\circ}$ was observed at $349.68 \mathrm{~K}$ and $268.77 \mathrm{~K}$, so the temperature difference is 80,91 degrees and better heat transfer performance than the base card design $23,22 \%$.

- The maximum and minimum temperature for heat exchangers with plate fins and tubes with a $45^{\circ}$ inclined arrangement of the elliptical tube was observed at $349.02 \mathrm{~K}$ and $270.03 \mathrm{~K}$, so the temperature difference is 78,9 degrees and improved heat transfer performance compared to the base card design $21,26 \%$.

- The maximum and minimum temperature for heat exchangers with plate fins and tubes with an arrangement of the elliptical tube inclined by $60^{\circ}$ was observed at $349.04 \mathrm{~K}$ and $273.58 \mathrm{~K}$, therefore the temperature difference is 75,46 degrees and better heat transfer performance than the base card design $17,67 \%$.

- The maximum and minimum temperature for heat exchangers with plate fins and tubes with an arrangement of the elliptical tube inclined by $90^{\circ}$ (vertical ellipse) was observed at $347.29 \mathrm{~K}$ and $274.39 \mathrm{~K}$, therefore the difference of temperature is 72.9 degrees and the heat transfer performance compared to base paper the improved design is $14.78 \%$.

From the above conclusions, it has been observed that the maximum heat transfer can be obtained from a plate and tube fin heat exchanger with an elliptical tube arrangement inclined by $30^{\circ}$ with a heat transfer capacity of $23.22 \%$ more than a circular plate heat exchanger. Therefore, it is recommended to obtain the heat transfer of the mix if using the plate fins and the tube heat exchanger with an inclined elliptical tube instead of the circular tube arrangement.

\section{VII.FUTURE WORK}


This work focuses on improving the heat transfer capacity of finned heat exchangers by changing their design. Although the study is conducted with great care, there is still room for improvement. Some suggestions for future studies may also be possible, such as:

- Finned tube heat exchangers with a circular tube and an elliptical arrangement are used in this worktop, but a different section can also be used.

- The thickness of the slats does not vary in the current job, so the thickness can also be the criterion in which it is possible to work in the future.

- The division of the tube bundle is constant in this work, a variable division can also be used.

- In this work elliptical tube angles of $30^{\circ}, 45^{\circ}, 60^{\circ}$ and $90^{\circ}$ are used, other angles can be used.

\section{REFERENCES}

[1] hang-Hyo Son, Joon-Young Kong "Heat Transfer Characteristics in a Plate-Fin Heat Exchanger with Single-Phase Flow" IEEA 2020: Proceedings of the 2020 The 9th International Conference on Informatics, Environment, Energy and Applications March 2020 .

[2] BasimFreegah, Ammar A.Hussain "CFD analysis of heat transfer enhancement in plate-fin heat sinks with fillet profile: Investigation of new designs" Thermal Science and Engineering Progress Volume 17, 1 June 2020, 100458.

[3] Máté PETRIK, Gábor SZEPESI "CFD analysis and heat transfer characteristics of finned tube heat exchangers" An International Journal for Engineering and Information Sciences, Vol. 14, No. 3, pp. 165-176, 2019.

[4] Abhishek Tiwari, Ram Raja, Rajesh Kumar "Performance Studies on Plate Fin Heat Exchanger with CFD Simulation" International Journal of Engineering and Innovative Technology (IJEIT) Volume 8, Issue 1, July 2018.

[5] Mohd Zeeshan, Sujit Nath "A CFD Analysis to Compare the Performances of Fin and Tube Heat Exchangers having Different Augmentation Techniques" International Journal of Applied Engineering Research ISSN 0973-4562 Volume 13, Number 6 pp. 327-333, 2018.

[6] S. Lowrey, Z. F. Sun "Experimental Investigation and Numerical Modelling of a Compact Wet Air-to-Air Plate Heat Exchanger" Applied Thermal Engineering 131 · November 2017.

[7] Ahmed Y Taha Al-Zubaydi, Guang Hong "CFD Modelling and Analysis of Different Designs Plate Heat Exchangers" Conference: 10th Australasian Heat and Mass Transfer Conference (AHMT2016), At Brisbane, Australia, 2016.

[8] L. Venkatesh, S. Arunraja, "3D CFD Study of the Effect of Inlet Air Flow Maldistribution on Plate-Fin-Tube Heat Exchanger" International Research Journal of Advanced Engineering and Science, Volume 1, Issue 4, pp. 67-70, 2016.

[9] Hamid Oualli at el. "Enhanced turbulence in the Taylor-Couette flow system" IX International Conference on Computational Heat and Mass Transfer, ICCHMT2016, Procedia Engineering 157 ( 2016 ) $443-450$.

[10] Xiang Peng, Zhenyu Liu \& Chan Qiu, Jianrong Tan "Effect of inlet flow maldistribution on the passage arrangement design of multistream plate-fin heat exchanger" Applied Thermal Engineering 103 (2016) 67-76.

[11] Rafal Wyczolkowski " Computational model of complex heat flow in the area of steel rectangular section" IX International
Conference on Computational Heat and Mass Transfer, ICCHMT2016, Procedia Engineering 157 ( 2016 ) 185 - 192.

[12] M.Khoshvaght-Aliabadi, S.Zangouei "Performance of a plate-fin heat exchanger with vortex-generator channels: 3D-CFD simulation and experimental validation" International Journal of Thermal Sciences Volume 88, February 2015, Pages 180-192. 